\title{
The Severe Respiratory Insufficiency Questionnaire for Subjects With COPD With Long-Term Oxygen Therapy
}

\author{
Stephan Walterspacher MD, Johanna July MD, Martin Kohlhäufl MD, Peter Rzehak PhD, and \\ Wolfram Windisch MD
}

\begin{abstract}
BACKGROUND: Respiratory insufficiency in COPD may present as hypoxic and/or hypercapnic respiratory failure treated with long-term oxygen therapy (LTOT) and/or noninvasive ventilation (NIV) with LTOT. The Severe Respiratory Insufficiency Questionnaire (SRI) is a tool for the assessment of health-related quality of life (HRQOL) in subjects receiving NIV. However, it remains unclear whether the SRI is also capable of assessing and discriminating HRQOL in subjects receiving LTOT. METHODS: Stable subjects with COPD receiving LTOT or NIV + LTOT (NIV) were prospectively recruited and completed the SRI, lung function tests, and blood gases. Confirmatory factor analysis for construct validity and internal consistency reliability were calculated. RESULTS: One hundred fifty-five subjects were included (113 LTOT, 42 NIV). The Cronbach $\alpha$ coefficient of the 7 subscales ranged between 0.69 and 0.89 (LTOT) and between 0.79 and 0.93 (NIV), respectively. In both groups, confirmatory factor analysis revealed a one-factor model for the SRI summary scale; in 5 subscales, one- or $\mathbf{2}$-factor models could be established. Group differences in the SRI subsets were all $P<.05$ (except for physical functioning) with higher scores in subjects receiving NIV. CONCLUSIONS: The SRI showed high reliability and validity in subjects with COPD receiving LTOT. Subjects receiving LTOT had lower SRI scores, indicating a poorer HRQOL compared with subjects with established NIV and LTOT. Key words: quality of life; COPD; oxygen inhalation therapy; noninvasive ventilation; chronic air flow obstruction; severe respiratory insufficiency questionnaire (SRI). [Respir Care 2016;61(9):1186-1191. (C) 2016 Daedalus Enterprises]
\end{abstract}

\section{Introduction}

Evaluation of health-related quality of life (HRQOL) is an established tool in measuring the burden of disease and
Drs Walterspacher and July are affiliated with the Clinic for Pneumology, Department of Internal Medicine, University Hospital Freiburg, Freiburg, Germany. Dr Kohlhäufl is affiliated with the Klinik Schillerhöhe, Center for Pulmonology and Thoracic Surgery, Academic Teaching Hospital of the University of Tübingen, Stuttgart-Gerlingen, Germany. Dr Rzehak is affiliated with Ludwig-Maximilians-University of Munich, Division of Metabolic and Nutritional Medicine, Dr von Hauner Children's Hospital, University of Munich Medical Centre, Munich, Germany. Dr Windisch is affiliated with the Department of Pneumology, Kliniken der Stadt Köln gGmbH, Cologne, University of Witten/Herdecke, Witten, Germany.

This study was conducted at the University Hospital Freiburg, Clinic for Pneumology, Germany and Klinik Schillerhöhe, Center for Pulmonology and Thoracic Surgery, Stuttgart-Gerlingen, Germany. the impact of treatment. ${ }^{1}$ Various tools and multidimensional questionnaires (eg, 36-item Medical Outcomes Study Short Form questionnaire or St George Respiratory Ques-

\footnotetext{
Supplementary material related to this paper is available at http:// www.rcjournal.com.
}

Dr Walterspacher has received grants from Weinmann, SapioLife, and Anamed. Dr Windisch has received open research grants from Weinmann, Vivisol, VitalAire, Respironics, Breas Medical, Heinen\&Löwenstein, and ResMed. The other authors have disclosed no conflicts of interest.

Dr Walterspacher presented a version of this work as a poster at the German Respiratory Society Congress, held March 29, 2014, in Bremen, Germany.

Correspondence: Wolfram Windisch MD, Department of Pneumology, Kliniken der Stadt Köln gGmbH, Ostmehrheimer Str. 200, 51109 Cologne, Germany.

DOI: $10.4187 /$ respcare. 04574 
tionnaire) have been established, but disease specificity is lacking in most cases. The Severe Respiratory Insufficiency Questionnaire (SRI) has been established and validated for the specific assessment of HRQOL in patients with hypercapnic respiratory failure receiving long-term noninvasive ventilation (NIV). ${ }^{2-7}$ The SRI has been translated into several languages and has become the standard tool for the assessment of HRQOL in patients receiving long-term NIV. ${ }^{8}$ Further details can be adapted from the homepage of the German Society of Pneumology and Mechanical Ventilation (http://www.pneumologie.de, Accessed March 16, 2016).

COPD is considered one of the major healthcare burdens worldwide, projected to rank fifth for disability-adjusted life years in 2030 by the World Health Organization. ${ }^{9}$ Lung function impairment is poorly reversible; therefore, treatment strategies must be aimed at stabilizing the disease progression and optimizing HRQOL. In advanced COPD, hypoxemic and/or hypercapnic respiratory failure may develop and may be treated with long-term oxygen therapy (LTOT) ${ }^{10}$ or NIV in conjunction with LTOT. ${ }^{11-13}$ In subjects with COPD receiving NIV and LTOT, the SRI has been established and validated as a disease- and treatment-specific tool for assessment of HRQOL, showing improvements in all subsets following the establishment of NIV.2,4,7

However, the HRQOL of patients with COPD receiving LTOT due solely to hypoxemic respiratory failure has not been determined by a disease-specific questionnaire. ${ }^{4}$ This observational study is aimed at evaluating HRQOL and examining the validity and reliability of the SRI questionnaire in subjects with COPD receiving LTOT compared with a matched group of subjects with COPD receiving NIV and LTOT (referred to as the NIV group in this work). This study aimed at establishing the validity and reliability of the SRI in subjects with COPD with sole hypoxemic respiratory failure. As a secondary end point, this study aimed at exploring differences in HRQOL in subjects with COPD with sole LTOT treatment compared with subjects with NIV and LTOT treatment. The null hypothesis was defined as no difference in mean scores of the SRI summary scale between both study groups.

\section{Methods}

The study protocol was approved by the institutional ethics committee of the University of Freiburg (Freiburg, Germany) and was performed in accordance with the standards laid down in the Declaration of Helsinki. Written informed consent was obtained from all subjects before the study. The study was registered in the German Clinical Trial Register (DRKS00006067).

\section{QUICK LOOK}

\section{Current knowledge}

The Severe Respiratory Insufficiency Questionnaire (SRI) has been developed and validated previously for the assessment of health-related quality of life in mechanically ventilated subjects. However, it remains unclear whether subjects also suffering from sole chronic hypoxemic respiratory failure with long-term oxygen therapy (LTOT) could also be adequately assessed by the SRI.

\section{What this paper contributes to our knowledge}

This study proved high psychometric properties (reliability and validity) of the SRI in subjects with COPD receiving LTOT. The SRI was also shown to be capable of distinguishing between subjects with COPD receiving LTOT and those receiving long-term noninvasive ventilation with the interesting finding that subjects receiving LTOT had lower SRI scores indicating a poorer health-related quality of life compared with subjects with established long-term noninvasive ventilation.

\section{Severe Respiratory Insufficiency Questionnaire}

The SRI includes 7 subscales with 49 items covering the aspects: respiratory complaints, physical functioning, attendant symptoms and sleep, social relationships, anxiety, psychological well-being, and social functioning. All subscales can be summarized into one summary scale. Subjects were asked to report on the circumstances of the last 2 weeks. ${ }^{2}$

Ratings were done on a 5-point Likert scale with a scaling method that measures either positive or negative responses with written statements graded from "strongly agree" to "strongly disagree." The score ranges can be reconstructed as values between 0 and 100 on each scale. Higher scores represent better HRQOL. ${ }^{2}$ Although the SRI has been shown to be valid for subjects with several conditions leading to chronic hypercapnic respiratory failure, ${ }^{2}$ the SRI has also been specifically validated for subjects with COPD. ${ }^{5}$

\section{Subjects}

Subjects with stable COPD according to the Global Initiative for Chronic Obstructive Lung Disease criteria and with chronic respiratory failure were studied and recruited in 2 study centers (University Hospital Freiburg and the academic teaching hospital Klinik Schillerhöhe [StuttgartGerlingen, Germany]). ${ }^{14}$ All subjects had to be established 
on LTOT or NIV with LTOT for $\geq 4$ weeks before inclusion and were receiving bronchodilator medication according to current guidelines. ${ }^{14}$ The group of subjects receiving NIV with LTOT are referred to as the NIV group. NIV was established with the aim to achieve normal values of $\mathrm{P}_{\mathrm{aCO}_{2}}$ (high-intensity NIV), as described previously. ${ }^{15,16}$ NIV was applied nocturnally for $\geq 6 \mathrm{~h}$ within $24 \mathrm{~h}$. Exclusion criteria included LTOT and/or NIV with LTOT due to other diseases, change of medication and/or exacerbations within the last 4 weeks, malignancies, or language comprehension disorders.

\section{Subject Recruitment}

The out-patient clinic and hospital information systems of the study centers were screened for eligible subjects. Attending subjects were directly included in the study; subjects found in the computer system were called, and, following instruction, the questionnaire was sent and returned by mail.

\section{Body Plethysmography and Blood Gas Sampling}

Body plethysmography was performed in all participants (MasterLab, CareFusion, Hoechberg, Germany) based on current recommendations. ${ }^{17}$ Only post-bronchodilation values are reported. Blood gases were collected from the arterialized earlobe (cobas b221; Roche Diagnostics, Grenzach-Wyhlen, Germany). Lung function data are reported from the last visit of the subjects in stable condition in the corresponding hospital. Blood gases for both groups were drawn from the arterialized earlobe at the individual established flow rate of oxygen before potential NIV application.

\section{Psychometric Properties}

The SRI was validated for 2 major psychometric properties in each group. Reliability was measured using the Cronbach $\alpha$ coefficient for assessment of each subscale and the summary scale internal consistency. ${ }^{1}$ Previous studies have validated the SRI for subjects receiving NIV with various diseases and also especially in subjects with COPD receiving NIV., ${ }^{2,5}$ For the LTOT group, validity was tested by scrutinizing the scale structure (construct validity); an explorative factor analysis was performed for each subscale and the SRI summary scale by using the principal components factor analysis method. Confirmatory factor analysis was performed to check the results gained by the explorative factor analysis. Further methodological details are reported in our previous study. ${ }^{4}$ Retesting of validity in subjects receiving LTOT guarantees, therefore, a high consistency of results and may allow group comparisons.

\section{Statistics}

Data analysis was performed using SAS/STAT 9 (SAS Institute, Cary, North Carolina) and Mplus (Mplus, Los Angeles, California). Sample size determination was calculated as follows: unpaired $t$ test, expected difference in SRI summary scale 5 points, estimated SD of SRI summary scale 10 points, power $0.8,2$-sided type- 1 error 0.05 . For rejection of $\mathrm{H}_{0}, 100$ subjects had to be included in the LTOT group and 30 subjects in the NIV group.

Statistical significance was assumed with a $P$ value $<.05$. Normality of the data was calculated using the KolmogorovSmirnov test. The unpaired $t$ test (normally distributed data) or Mann-Whitney rank-sum test (non-normally distributed data) was used for comparing both groups. Sex differences between groups were calculated using the Fisher exact test.

Reliability was assessed using the Cronbach $\alpha$ coefficient to ensure that each rating scale was consistent (internal consistency) using the SAS procedure proc corr. ${ }^{18}$ Cronbach $\alpha>0.7$ was assumed as high internal consistency. Validity was assessed using principal and confirmatory factor analysis by the proc factor procedure of SAS and Mplus, respectively. ${ }^{4}$

\section{Results}

Demographic, lung function, and blood gas data are presented in Table 1. Neither group differed in anthropomorphic characteristics, oxygen demand, or duration of NIV or LTOT therapy. Subjects receiving NIV presented a higher degree of air-flow limitation, reduced vital capacity, and higher $\mathrm{P}_{\mathrm{aCO}}$ values.

\section{Severe Respiratory Insufficiency Questionnaire Ratings}

Ratings of the SRI for each SRI subscale and the summary scale are presented in Table 2 for the entire study group and for each study group, respectively. For the entire study group, the mean values of the SRI varied around the mean. The lowest values were in the subscale physical functioning, whereas the highest rating was in social relationships. In the group comparison, there were statistically higher ratings in the NIV group, except for the SRI physical functioning subscale.

\section{Reliability}

The Cronbach $\alpha$ exceeded 0.7 in both groups except for in the SRI attendant symptoms and sleep subscale (see Table 3), indicating high internal consistency reliability. Compared with the Cronbach $\alpha$ of the subscales ranging from 0.69 to 0.89 , the summary scale ranged even higher (0.89-0.99). 
Table 1. Demographic and Lung Function Data

\begin{tabular}{|c|c|c|c|c|}
\hline Characteristics & Total $(N=155)$ & LTOT $(n=113)$ & NIV $(n=42)$ & $P($ LTOT vs NIV) \\
\hline Female/male sex, $n$ & $67 / 88$ & $53 / 60$ & $14 / 28$ & .15 \\
\hline Age, mean \pm SD y & $62.9 \pm 8.1$ & $62.6 \pm 8$ & $63.7 \pm 8.3$ & .46 \\
\hline Height, mean $\pm \mathrm{SD} \mathrm{m}$ & $1.67 \pm 0.09$ & $1.68 \pm 0.09$ & $1.7 \pm 0.08$ & .12 \\
\hline Weight, mean \pm SD kg & $68.4 \pm 17.8$ & $67.2 \pm 17.5$ & $71.5 \pm 18.4$ & .18 \\
\hline $\mathrm{BMI}$, mean $\pm \mathrm{SD} \mathrm{kg} / \mathrm{m}^{2}$ & $23.9 \pm 5.2$ & $23.7 \pm 5.1$ & $24.5 \pm 5.6$ & .36 \\
\hline Treatment duration $($ LTOT + NIV), mean \pm SD mo & $28.3 \pm 25.4$ & $30.2 \pm 25.3$ & $22.1 \pm 25.7$ & .13 \\
\hline Oxygen demand, mean $\pm \mathrm{SD}$ L/min & $2.4 \pm 1$ & $2.5 \pm 0.8$ & $2.4 \pm 1.3$ & .77 \\
\hline Previous exacerbation with hospitalization, mean $\pm \mathrm{SD}$ weeks & $61.4 \pm 89.3$ & $61 \pm 93.9$ & $62.5 \pm 76.5$ & .93 \\
\hline $\mathrm{RV}$, mean $\pm \mathrm{SD} \%$ predicted & $226.4 \pm 59$ & $221.1 \pm 57.9$ & $241 \pm 60.1$ & .064 \\
\hline $\mathrm{FVC}$, mean $\pm \mathrm{SD} \%$ predicted & $56.7 \pm 14.8$ & $58.6 \pm 15.2$ & $51.7 \pm 12.6$ & .01 \\
\hline $\mathrm{TLC}$, mean $\pm \mathrm{SD} \%$ predicted & $114.9 \pm 18$ & $114.5 \pm 15.6$ & $115.9 \pm 23.2$ & .70 \\
\hline $\mathrm{FEV}_{1}$, mean $\pm \mathrm{SD} \%$ predicted & $27.6 \pm 8.5$ & $28.4 \pm 8.3$ & $25.4 \pm 8.7$ & .053 \\
\hline $\mathrm{FEV}_{1} / \mathrm{FVC}$ & $36.3 \pm 7.9$ & $36.7 \pm 8.1$ & $35.3 \pm 7.5$ & .35 \\
\hline $\mathrm{pH}$ & $7.41 \pm 0.03$ & $7.42 \pm 0.02$ & $7.41 \pm 0.03$ & .10 \\
\hline $\mathrm{P}_{\mathrm{aCO}_{2}} \mathrm{~mm} \mathrm{Hg}$ & $44.9 \pm 6.1$ & $43.9 \pm 5.6$ & $47.6 \pm 6.7$ & .01 \\
\hline $\mathrm{P}_{\mathrm{aO}_{2}} \mathrm{~mm} \mathrm{Hg}$ & $68.8 \pm 10.3$ & $68.3 \pm 9.9$ & $70.2 \pm 11.5$ & .33 \\
\hline $\begin{array}{l}\text { All values are presented as mean with standard deviation. } \\
\text { BMI = body mass index } \\
\text { LTOT = long-term oxygen therapy } \\
\text { NIV = noninvasive ventilation } \\
\text { RV = residual volume } \\
\text { TLC = total lung capacity }\end{array}$ & & & & \\
\hline
\end{tabular}

Table 2. Severe Respiratory Insufficiency Questionnaire

\begin{tabular}{|c|c|c|c|c|c|c|c|}
\hline \multirow{2}{*}{ Scale } & \multicolumn{2}{|c|}{$\begin{array}{c}\text { Total } \\
(N=155)\end{array}$} & \multicolumn{2}{|c|}{$\begin{array}{c}\text { LTOT } \\
(n=113)\end{array}$} & \multicolumn{2}{|c|}{$\begin{array}{c}\text { NIV } \\
(n=42)\end{array}$} & \multirow{2}{*}{$\begin{array}{c}P \text { (LTOT } \\
\text { vs NIV) }\end{array}$} \\
\hline & Mean & SD & Mean & SD & Mean & SD & \\
\hline SRI_RC & 47.6 & 18.6 & 46.1 & 18.1 & 51.8 & 19.2 & .43 \\
\hline SRI_PF & 34.3 & 19.1 & 33.6 & 17.5 & 35.7 & 23.1 & .30 \\
\hline SRI_AS & 57.6 & 18.8 & 55.5 & 18.1 & 63 & 19.6 & .01 \\
\hline SRI_SR & 61.7 & 21.2 & 59.8 & 20.7 & 66.7 & 22.1 & .037 \\
\hline SRI_AX & 42.5 & 24.5 & 39.3 & 23.8 & 51.2 & 24.6 & $<.01$ \\
\hline SRI_WB & 51.4 & 21 & 49.4 & 19.9 & 56.6 & 23.2 & .03 \\
\hline SRI_SF & 42.4 & 21.7 & 40.6 & 20.9 & 47.2 & 23.1 & .045 \\
\hline SRI_SS & 48.2 & 16.7 & 46.3 & 15.6 & 53.2 & 18.6 & .01 \\
\hline
\end{tabular}

LTOT $=$ long-term oxygen therapy

NIV $=$ noninvasive ventilation

$\mathrm{SRI}=$ Severe Respiratory Insufficiency Questionnaire

$\mathrm{RC}=$ respiratory complaints

$\mathrm{PF}=$ physical functioning

$\mathrm{AS}=$ attendant symptoms and sleep

$\mathrm{SR}=$ social relationships

$\mathrm{AX}=$ anxiety

$\mathrm{WB}=$ psychological well-being

$\mathrm{SF}=$ social functioning

$\mathrm{SS}=$ summary scale

\section{Validity}

Principal confirmatory factor analysis confirmed a one-factor model for the SRI summary scale in the whole group and each subgroup, respectively. One-, 2-, and
Table 3. Cronbach $\alpha$ Reliability

\begin{tabular}{|c|c|c|c|c|c|c|c|}
\hline \multirow{2}{*}{ Scale } & \multirow{2}{*}{ Items } & \multicolumn{2}{|c|}{$\begin{array}{c}\text { Total } \\
(N=155)\end{array}$} & \multicolumn{2}{|c|}{$\begin{array}{c}\text { LTOT } \\
(n=113)\end{array}$} & \multicolumn{2}{|c|}{$\begin{array}{c}\text { NIV } \\
(n=42)\end{array}$} \\
\hline & & $n$ & $\alpha$ & $n$ & $\alpha$ & $n$ & $\alpha$ \\
\hline SRI_RC & 8 & 151 & 0.80 & 110 & 0.78 & 41 & 0.82 \\
\hline SRI_PF & 6 & 154 & 0.80 & 112 & 0.76 & 42 & 0.87 \\
\hline SRI_AS & 7 & 149 & 0.70 & 107 & 0.69 & 42 & 0.69 \\
\hline SRI_SR & 6 & 143 & 0.78 & 105 & 0.76 & 38 & 0.84 \\
\hline SRI_AX & 5 & 148 & 0.78 & 110 & 0.77 & 38 & 0.79 \\
\hline SRI_WB & 9 & 148 & 0.87 & 109 & 0.89 & 39 & 0.87 \\
\hline SRI_SF & 8 & 131 & 0.86 & 98 & 0.87 & 33 & 0.83 \\
\hline SRI_SS & 7 subscales & 155 & 0.90 & 113 & 0.89 & 42 & 0.93 \\
\hline
\end{tabular}

LTOT $=$ long-term oxygen therapy

$\mathrm{NIV}=$ noninvasive ventilation

SRI $=$ Severe Respiratory Insufficiency Questionnaire

$\mathrm{RC}=$ respiratory complaints

$\mathrm{PF}=$ physical functioning

$\mathrm{AS}=$ attendant symptoms and sleep

$\mathrm{SR}=$ social relationships

$\mathrm{AX}=$ anxiety

$\mathrm{WB}=$ psychological well-being

$\mathrm{SF}=$ social functioning

$\mathrm{SS}=$ summary scale

4-factor models could be conformed in the SRI subscales in the LTOT and NIV subgroups (see Table 4). In multifactor models, it is suggested that in a subscale, 2 or 4 other subscales may contribute to the reported impairment. Further details are reported in the online 
Table 4. Principal Confirmatory Factor Analysis

\begin{tabular}{|c|c|c|c|c|c|c|}
\hline \multirow{2}{*}{ Scale } & \multicolumn{2}{|c|}{$\begin{array}{c}\text { Total } \\
(N=155)\end{array}$} & \multicolumn{2}{|c|}{$\begin{array}{c}\text { LTOT } \\
(n=113)\end{array}$} & \multicolumn{2}{|c|}{$\begin{array}{c}\text { NIV } \\
(n=42)\end{array}$} \\
\hline & $n$ & $\mathrm{r}$ & $n$ & $\mathrm{r}$ & $n$ & $\mathrm{r}$ \\
\hline SRI_RC & 4 & $0.2-0.8$ & 4 & $0.18-0.74$ & 1 & \\
\hline SRI_PF & 2 & 0.69 & 2 & 0.62 & 1 & \\
\hline SRI_AS & 2 & 0.46 & 1 & & 2 & 0.38 \\
\hline SRI_SR & 2 & 0.61 & 2 & 0.5 & 1 & \\
\hline SRI_AX & 2 & 0.6 & 2 & 0.56 & 1 & \\
\hline SRI_WB & 2 & 0.72 & 2 & 0.73 & 2 & 0.82 \\
\hline SRI_SF & 2 & 0.85 & 2 & 0.81 & 2 & 0.79 \\
\hline SRI_SS & 1 & & 1 & 1 & & \\
\hline \multicolumn{7}{|c|}{ LTOT $=$ long-term oxygen therapy } \\
\hline \multicolumn{7}{|c|}{ NIV = noninvasive ventilation } \\
\hline \multicolumn{7}{|c|}{ SRI $=$ Severe Respiratory Insufficiency Questionnaire } \\
\hline \multicolumn{7}{|c|}{$\mathrm{RC}=$ respiratory complaints } \\
\hline \multicolumn{7}{|c|}{$\mathrm{PF}=$ physical functioning } \\
\hline \multicolumn{7}{|c|}{$\mathrm{AS}=$ attendant symptoms and sleep } \\
\hline \multirow{2}{*}{\multicolumn{7}{|c|}{$\begin{array}{l}S R=\text { social relationships } \\
\mathrm{AX}=\text { anxiety }\end{array}$}} \\
\hline \multirow{2}{*}{\multicolumn{7}{|c|}{$\begin{array}{l}\mathrm{AX}=\text { anxiety } \\
\mathrm{WB}=\text { psychological well-being }\end{array}$}} \\
\hline & & & & & & \\
\hline \multicolumn{3}{|c|}{$\begin{array}{l}\mathrm{WB}=\text { psychological well-being } \\
\mathrm{SF}=\text { social functioning }\end{array}$} & & & & \\
\hline SS $=$ summar & & & & & & \\
\hline
\end{tabular}

supplement (see the supplementary materials at http:// www.rcjournal.com).

\section{Discussion}

The present study for the first time evaluated the SRI for subjects with COPD with chronic hypoxemic respiratory failure receiving LTOT. The SRI proved high reliability and validity in the LTOT subject group. In comparison with subjects with COPD receiving NIV and LTOT, subjects with sole hypoxic respiratory failure receiving LTOT exhibited a diminished HRQOL.

\section{Reliability}

The Cronbach $\alpha$ revealed high internal consistency reliability for all subscales in each group (.7-.93) except for the attendant symptoms and sleep subscale (.69). However, these data are comparable and even higher compared with previous studies evaluating the SRI., ${ }^{2,5,6,19,20}$ A higher Cronbach $\alpha$ coefficient in the summary scale might be due to an increased number of analyzed items, as described previously. ${ }^{4}$

\section{Validity}

The high rate of internal correlations with a 4-factor model (respiratory complaints) and 2-factor models for the other subscales in the total study group proves that HRQOL is multidimensional and complex in its assessment. ${ }^{5}$ How- ever, these findings are consistent with the previous validation studies employing principal component factor analysis in which no subscales with a single-factor model could be established in subjects with COPD. ${ }^{5,19}$

Construct validity has repeatedly been shown to be high for the SRI when applied in subjects with chronic hypercapnic respiratory failure ${ }^{5,6}$ and is now for the first time also validated with a high validity for subjects with sole hypoxic respiratory failure receiving LTOT.

\section{HRQOL}

The total study group proved to be comparable, regarding disease severity as judged by lung function parameters and HRQOL, with the previous studies evaluating the SRI in subjects with COPD receiving NIV. ${ }^{4,5,21}$ As shown in the validation study of the SRI for subjects with COPD receiving NIV $^{5}$ and demonstrated in this study for the NIV group, also subjects with COPD receiving LTOT achieved the lowest values in the physical functioning subscale, whereas the social relationships subscale ranked highest. However, subscale ratings were consistently lower in the LTOT group, indicating that HRQOL was more severely affected. This is surprising, since NIV application is known for more pronounced side effects, such as mouth dryness, skin irritations, or ulcers. ${ }^{21,22}$ Previous reports have already demonstrated diminished HRQOL in subjects with COPD with chronic hypoxic respiratory failure that is not ameliorated by LTOT application. ${ }^{10}$

Although both groups were matched for anthropometric data, lung function parameters differed in both groups. Of note, the LTOT group had less pronounced air-flow obstruction and hyperinflation but experienced a more diminished HRQOL when compared with the NIV group. However, it may be speculative whether the extent of airflow obstruction in this group would solely explain the diminished HRQOL or whether the effects of NIV by resting the respiratory muscles and reducing the work of breathing during NIV application may lead to an enhanced HRQOL. ${ }^{23}$ Respiratory muscle function impairment is known to occur not only in subjects with COPD with hypercapnic respiratory failure but also in subjects with COPD in early disease stages, ${ }^{24,25}$ and NIV application may therefore account for HRQOL benefits. It is of interest that the NIV group still presented with elevated $\mathrm{P}_{\mathrm{aCO}_{2}}$ levels when compared with the LTOT group despite highintensity NIV, aiming to reduce $\mathrm{P}_{\mathrm{aCO}_{2}}$ to normal values..$^{15,16}$ It may be speculated that the differences between both groups could have been even more pronounced if $\mathrm{P}_{\mathrm{aCO}_{2}}$ were completely normalized by NIV application.

\section{Limitations}

The SRI has not been retested against other tools of HRQOL measurement (eg, the 36-item Medical Outcomes 


\section{SEVERE Respiratory InSUFFICIENCy QUESTIONNAIRE IN COPD}

Study Short Form questionnaire or St George Respiratory Questionnaire). However, in previous studies, the SRI has proven to be of higher specificity in evaluating HRQOL in subjects with chronic hypercapnic respiratory failure. . $^{3,21}$

This study does not employ a longitudinal follow-up or retest reproducibility assessment of subjects receiving LTOT or NIV. However, a longitudinal design would have been beyond the scope of this work addressing the validation of the already established SRI questionnaire in a distinct subset of subjects with COPD with sole hypoxemic respiratory failure.

The influence of comorbidities, such as arterial hypertension or cardiac insufficiency, on HRQOL in the LTOT or NIV group has not been addressed and may have influenced the results. However, this bias is true for both groups studied, and any possible confounding influence should involve both groups. Furthermore, this study was only powered for detecting differences in the SRI; further confounding variables would have greatly increased the sample size. The confounding effect of comorbidities on HRQOL in subjects with COPD with LTOT or NIV is an important question and should be subject to further studies.

\section{Conclusions}

The SRI proved high reliability and validity in subjects with COPD with chronic hypoxemic respiratory failure receiving LTOT. Subjects receiving LTOT had lower scores in the SRI, indicating a poorer HRQOL compared with subjects with established NIV and LTOT.

\section{REFERENCES}

1. Testa MA, Simonson DC. Assessment of quality-of-life outcomes. N Engl J Med 1996;334(13):835-840.

2. Windisch W, Freidel K, Schucher B, Baumann H, Wiebel M, Matthys H, Petermann F. The Severe Respiratory Insufficiency (SRI) Questionnaire: a specific measure of health-related quality of life in patients receiving home mechanical ventilation. J Clin Epidemiol 2003;56(8):752-759.

3. Windisch W, Freidel K, Schucher B, Baumann H, Wiebel M, Matthys H Petermann F. Evaluation of health-related quality of life using the MOS 36-Item Short-Form Health Status Survey in patients receiving noninvasive positive pressure ventilation. Intensive Care Med 2003;29(4):615-621.

4. Windisch W. Impact of home mechanical ventilation on health-related quality of life. Eur Respir J 2008;32(5):1328-1336.

5. Windisch W, Budweiser S, Heinemann F, Pfeifer M, Rzehak P. The Severe Respiratory Insufficiency Questionnaire was valid for COPD patients with severe chronic respiratory failure. J Clin Epidemiol 2008;61(8):848-853.

6. Duiverman ML, Wempe JB, Bladder G, Jansen DF, Kerstjens HA, Zijlstra JG, Wijkstra PJ. Nocturnal non-invasive ventilation in addition to rehabilitation in hypercapnic patients with COPD. Thorax 2008;63(12):1052-1057.
7. Köhnlein T, Windisch W, Köhler D, Drabik A, Geiseler J, Hartl S, et al. Non-invasive positive pressure ventilation for the treatment of severe stable chronic obstructive pulmonary disease: a prospective, multicentre, randomised, controlled clinical trial. Lancet Respir Med 2014;2(9):698-705.

8. Struik FM, Kerstjens HAM, Bladder G, Sprooten R, Zijnen M, Asin $\mathrm{J}$, et al. The Severe Respiratory Insufficiency Questionnaire scored best in the assessment of health-related quality of life in chronic obstructive pulmonary disease. J Clin Epidemiol 2013;66(10):11661174.

9. World Health Organization. The Global burden of disease: 2004 update. Geneva, Switzerland: World Health Organization, 2008. http://www.who.int/healthinfo/global_burden_disease/GBD_report_ 2004update_full.pdf?ua=1. Accessed March 2, 2016.

10. Nocturnal Oxygen Therapy Trial Group. Continuous or nocturnal oxygen therapy in hypoxemic chronic obstructive lung disease: a clinical trial. Ann Intern Med 1980;93(3):391-398.

11. Funk GC, Breyer MK, Burghuber OC, Kink E, Kirchheiner K, Kohansal $\mathrm{R}$, et al. Long-term non-invasive ventilation in COPD after acute-on-chronic respiratory failure. Respir Med 2011;105(3):427434.

12. Windisch W, Walterspacher S, Siemon K, Geiseler J, Sitter H. Guidelines for non-invasive and invasive mechanical ventilation for treatment of chronic respiratory failure. Pneumologie 2010;64(10):640652 .

13. NICE Guidance. Chronic obstructive pulmonary disease in over 16s: diagnosis and management. http://www.nice.org.uk/guidance/ CG101. Accessed December 13, 2015.

14. Global Initiative for Chronic Obstructive Lung Disease. Global strategy for the diagnosis, management, and prevention of chronic obstructive pulmonary disease. Updated 2015. http://www.goldcopd.org/ uploads/users/files/GOLD_Report_2015_Feb18.pdf.

15. Windisch W, Dreher M, Storre JH, Sorichter S. Nocturnal noninvasive positive pressure ventilation: physiological effects on spontaneous breathing. Respir Physiol Neurobiol 2006;150(2):251-260.

16. Dreher M, Storre JH, Schmoor C, Windisch W. High-intensity versus low-intensity non-invasive ventilation in patients with stable hypercapnic COPD: a randomised crossover trial. Thorax 2010;65(4): 303-308.

17. Miller MR. Standardisation of spirometry. Eur Respir J 2005;26(2): 319-338.

18. Nunnally JC, Bernstein IH. Psychometric Theory, 3rd edition. New York: McGraw-Hill, 1994.

19. Ghosh D, Rzehak P, Elliott MW, Windisch W. Validation of the English Severe Respiratory Insufficiency Questionnaire. Eur Respir J 2012;40(2):408-415.

20. López-Campos JL, Failde I, Masa JF, Benítez-Moya JM, Barrot E, Ayerbe R, et al. Transculturally adapted Spanish SRI questionnaire for home mechanically ventilated patients was viable, valid, and reliable. J Clin Epidemiol 2008;61(10):1061-1066.

21. Windisch W, Quality of life in home mechanical ventilation study group. Impact of home mechanical ventilation on health-related quality of life. Eur Respir J 2008;32(5):1328-1336.

22. Mehta S, Hill NS. Noninvasive ventilation. Am J Respir Crit Care Med 2001;163(2):540-577.

23. Lukácsovits J, Carlucci A, Hill N, Ceriana P, Pisani L, Schreiber A, et al. Physiological changes during low- and high-intensity noninvasive ventilation. Eur Respir J 2011;39(4):869-875.

24. Kabitz HJ, Walterspacher S, Walker D, Windisch W. Inspiratory muscle strength in chronic obstructive pulmonary disease depending on disease severity. Clin Sci 2007;113(5):243-249.

25. Ottenheijm CA, Heunks LM, Sieck GC, Zhan WZ, Jansen SM, Degens $\mathrm{H}$, et al. Diaphragm dysfunction in chronic obstructive pulmonary disease. Am J Respir Crit Care Med 2005;172(2):200-205. 